\title{
Persistence to continuous punishment as a function of amount of reinforcement'
}

DOUGLAS P. FERRARO

UNIVERSITY OF NEW MEXICO

Four groups of rats were trained to make a bar-press response for either $0.01,0.02,0.04$, or $0.08 \mathrm{cc}$ of water reinforcement for each response. When electric shock punishment was added to each response, the amount of response suppression induced by punishment was inversely related to the amount of reinforcement maintaining behavior.

In most free-operant punishment experiments, a specified response is increased in strength by positive reinforcement prior to the introduction of responsecontingent aversive stimulation. Regardless of whether the reinforcement procedure is terminated or continues to be maintained after the introduction of punishment, we might expect the effects of punishment to be determined, in part, by parameters of the initial reinforcement procedure. Considerable evidence exists which suggests that the schedule, frequency, and number of reinforcements do influence the amount and type of response suppression induced by punishment (Lawson \& Born, 1964; Azirin \& Holz, 1966). However, no experimentation has been performed in the free-operant situation to determine the effectiveness of punishment as a function of the quality, amount, or delay of reinforcement. The present study investigates the influence of one of these variables, that of amount of reinforcement, on the initial suppressive effects of continuous punishment.

Method

The Ss were 12 130-day-old male hooded rats from the New Mexico breeding colony. Each S was maintained in an individual living cage throughout the study and was weighed daily at the same time. Two weeks prior to experimentation, each S was exposed to a 24-hr. water deprivation rhythm during which food was freely accessible, but only the amount of water necessary to maintain S's body weight at $80 \%$ of its free-feeding weight was provided. This deprivation schedule remained in effect during the entire experiment.

The experimental chamber was a Scientific Prototype rat box equipped with a single response lever and Lehigh Valley liquid dipper which delivered reinforcements. The chamber floor consisted of seven equally spaced stainless steel grids which were wired to a Grason-Stadler shock generator and scrambler. Punishment consisted of $0.5 \mathrm{sec}$. of a 0.25 ma electric shock delivered through the grid floor and response lever. The experimental chamber was housed in a ventilated, sound-resistant shell. Controlling and recording equipment included transistorized digital logic modules, supportive relay circuitry, and electromagnetic counters.
On the day immediately following the 2-week period of acclimation to the $24-\mathrm{hr}$. water deprivation schedule, the $12 \mathrm{Ss}$ were randomly assigned to groups of three animals. Each group was assigned a different amount of reinforcement from among the values of $0.01,0.02$, 0.04 , and $0.08 \mathrm{cc}$ of water. The groups were then given one 15-min. session of dipper approach training to water reinforcement. A positive reinforcement throughout the experiment consisted of a 3-sec. presentation of the dipper filled with the amount of water designated for each group of rats. The next day each $S$ was trained to press the lever and allowed to procure 100 reinforcements on a schedule in which every response was positively reinforced. The four groups of rats were then exposed to five additional daily continuous reinforcement sessions. Each session was terminated after 100 reinforcements had been obtained so that every rat had received a total of 600 reinforcements consisting of either $0.01,0.02,0.04$, or $0.08 \mathrm{cc}$ of water.

After this initial training, a continuous punishment contingency was superimposed on the baseline behavior which continued to be maintained by positive reinforcement. Thus, every response was followed by both water reinforcement and electric shock punishment. This concurrent contingency of continuous reinforcement and continuous punishment remained in effect for five

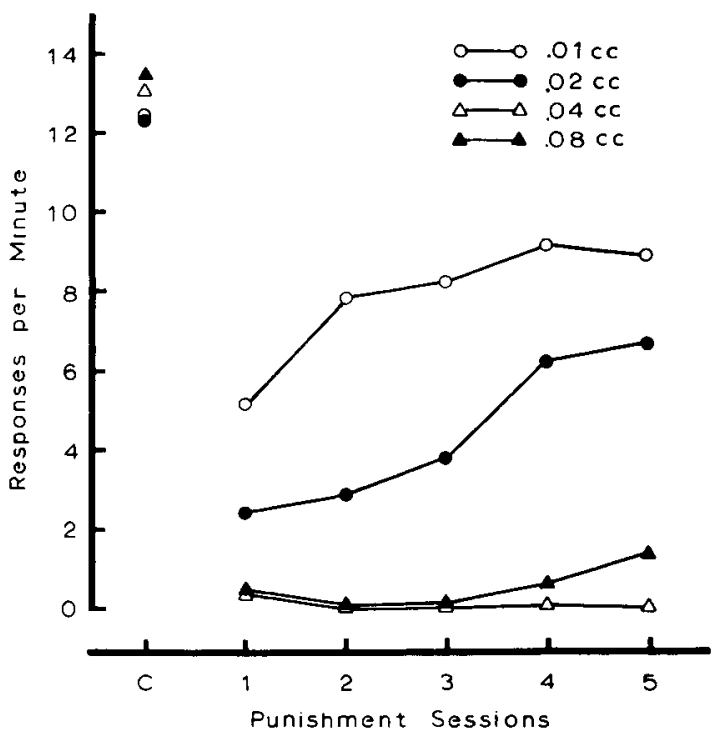

Fig. 1. Average response rate for the non-punishment sessions (Session $C$ ) and for the five punishment sessions plotted separately for each amount of reinforcement. 
consecutive daily sessions. During the punishment phase of the experiment, a session was terminated after 100 reinforcements had been obtained or after $15 \mathrm{~min}$. had elapsed.

\section{Results and Discussion}

The average response rates for the five sessions prior to punishment are plotted separately for each reinforcement amount as the non-punishment control session in Fig. 1. Statistical analysis showed that no significant differences existed among the group response rates in the absence of punishment. However, rates of response under punishment were differentially affected by amount of reinforcement. The functions in Fig. 1 show that amount of punishment suppression was inversely related to amount of reinforcement; that is, greater response persistence occurred at the smaller than at the larger amounts of reinforcement. A Friedman analysis of variance applied across punishment sessions showed that the differences in suppression obtained with the various reinforcement amounts were significant $\left(\chi_{\rho}^{2}=15, \mathrm{df}=.3, \mathrm{p}<.01\right)$.

Although both the $0.04 \mathrm{cc}$ and $0.08 \mathrm{cc}$ reinforcement groups clearly showed less response persistence than the smaller reinforcement groups, the response rate for the $0.04 \mathrm{cc}$ group was somewhat less than for the $0.08 \mathrm{cc}$ group. This suggests that response persistence under punishment and amount of reinforcement may be nonmonotonically related. However, the small difference between these groups indicates that additional data are necessary before the exact function shape at large amounts of reinforcements can be determined.

Regardless of whether or not the present functions are monotonic, the data obtained are not in agreement with the report by Bower \& Miller (1960) that greater persistence to punishment conflict occurs at large rather than at small amounts of reinforcement. However, direct comparisons between their study and the present one are largely negated due to considerable differences in punishment procedures. On the other hand, the response decrement obtained here under punishment is similar to that sometimes obtained under extinction after different amounts of reinforcement (e.g., Snyder \& Hulse, 1961; Wagner, 1961) and is consistent with recent evidence indicating that response persistence under extinction or punishment is not always directly related to number of reinforcements (North \& Stimmel, 1960; Lawson \& Born, 1964). In this connection, the present data may be considered as additional support for the growing body of data which indicates that punishment and extinction produce similar behavioral changes in a variety of situations (cf., Wagner, 1966).

\section{References}

Azrin, N. H., \& Holz, W. C. Punishment. In W. K. Honig (Ed.), Operant behavior: areas of research and application. New York: Appleton-Century-Crofts, 1966. Pp. 380-447.

Bower, G. H., \& Miller, N. E. Effects of amount of reward on strength of approach in an approach-avoidance conflict. $J$. comp. physiol. Psychol., 1960, 53, 59-62.

Lawson, R., \& Bom, D. G. Recovery from punishment as a function of number of pre-punishment reinforcements. Psychon. Sci., $1964,1,269-270$.

North, A. F., \& Stimmel, D. T. Extinction of an instrumental response following a large number of reinforcements. Psychol. Rep., 1960, 6, 227-234.

Snyder, H. L., \& Hulse, S. H. Effect of volume of reinforcement and number of consummatory responses on licking and runway behavior. J. exp. Psychol., 1961, 61, 474-479.

Wagner, A. R. Effects of amount and percentage of reinforcement and number of acquisition trials on conditioning and extinction. J. exp. Psychol., 1961, 62, 234-242.

Wagner, A. R. Frustration and punishment. In R. N. Haber (Ed.), Current research in motivation. New York: Holt, 1966. Pp. 229238.

\section{Noie}

1. This investigation was supported in part by a. grant from the University of New Mexico. The author is indebted to Professor F. A. Logan for his cooperation in making research facilities available and to $D$. Perkins for his assistance in the research. 